\title{
Technology Transfer, Merger and Joint Venture: A Comparative Welfare Analysis*
}

\author{
Prithvijit Roy \\ Tarun Kabiraj \\ Arijit Mukherjee \\ Indian Statistical Institute
}

\begin{abstract}
We consider a framework where initially a foreign firm and a few domestic firms are competing in a homogenous product local market. The foreign firm has a lower marginal cost of production relative to the domestic firms. We study then possibility of a bilateral agreement between the foreign firm and a local firm on each of technology transfer, merger and joint venture. Given the optimal behavior of the foreign firm, the paper also examines welfare implica tions of each such collaborative deal. D epending on cost asymmetry it is always profitable for the foreign firm to go for the one or the other deal. B ut the local government generally encourages new firm joint venture formation. The degree of cost asymmetry and the number of firms in the market play an impor tant role in this analysis. (JE L Classification: D43; L13; F23.) ४Key Words: technology transfer; merger; joint venture.>
\end{abstract}

* Correspondence Address: Tarun Kabiraj, Economic Research Unit, Indian Statistical Institute, 203 B. T. Road, Calcutta 700 035, India, (Fax) +91-33-577-6680, (E-mail) tarun @isical.ac.in; We would like to thank an anonymous referee of this Journal for comments and suggestions. Discussions with Sudipto Dasgupta and Sharmila Baner jee were also helpful. We shall be held responsible for any remaining errors which may have gone unnoticed in the pages that follow.

(c)1999 - Institute for International Economics, Sejong Institution. All rights reserved. 


\section{Introduction}

The foreign-based multinationals typically have a choice of alternative modes of entry into the domestic market of developing countries, e.g., direct export of goods, foreign direct investment, technology transfer, merger or joint venture. These issues are already well documented in the literature. While Caves [1971, 1982], Telesio [1979] and Baranson [1978] discuss the optimal entry strategies from the perspective of the foreign multinationals, Bardhan [1982], Tang and Yu [1990] and Kabiraj [1993] consider their implications for domestic welfare. In particular, the paper by Tang and Yu highlights the conflicts of interests between the foreign-based multinationals and the local government on the issue of optimal entry strategy. Obviously, in all these papers, the multinational companies (M NC henceforth) are not initially operating in the local market but are looking for an entry.

In this paper we are interested in a situation where a foreign-based M NC is already operating in the market through its wholly-owned subsidiary and is now looking forward to an expansion in the same market. To be precise, we are assuming that the subsidiary of a foreign M NC already existent in the local market is competing in homogeneous good with other local firms, and now the foreign firm wants to expand its profits through a bilateral (collaboration) agreement with a local firm. We consider three alternative collaboration possibilities, viz, technology transfer, horizontal merger and joint venture. The foreign firm is assumed to have a superior production technology and hence we study the possibility of each such bilateral agreement and the corresponding welfare implication based on the cost differential between the advanced and the backward firms. Our analysis brings into focus the role of cost asymmetry in the choice of the collaboration arrangement of the MNC.

In a recent paper $M$ arjit, Kabiraj and $M$ ukherjee [1999] consider an oligopolistic framework with $n$ advanced firms and $m$ backward firms which are competing in the same market. That paper studies the role of cost asymmetry and initial market structure to determine the profitability of a bilateral technology transfer and merger between two asymmetric firms. However, in their paper the firms have no country specific characterization. Also, $\mathrm{M}$ arjit et al. do not have any welfare analysis. Our paper, in contrast, takes into 
account domestic welfare analysis in a situation where one of these firms is foreign based, and is also technologically more advanced. The present paper then goes on to show the conflict between the local government and the multinational depending on the cost asymmetry and the number of firms in the local market. In contrast to $\mathrm{M}$ arjit et al., in addition to the possibility of technology transfer and merger, we also consider the possibility of a joint venture formation between the foreign firm and a local firm.

The distinction between the alternative collaboration arrangements is as follows. In a technology transfer agreement $(T)$, the foreign firm transfers its superior production knowhow to a backward local firm and charges an appropriate price (M arjit [1990], Katz and Shapiro [1985]). In the post transfer situation both the transferor and the transferee have superior technologies and all the other firms in the industry have backward technology. Thus, the number of potential competitors in the industry remains unchanged.

In a horizontal merger (M), the constituent firms lose their independent identities, and the merged firm, which operates with the superior technology, is concerned with the joint profit (Salant, Switzer and Reynolds [1983], Long and Vousden [1995]). So, the number of potential competitors in the industry is reduced by one.

Under a joint venture $(\mathrm{J})$, the foreign firm and the domestic firm enter into a contract to form a new firm which will compete in the same market (Kwoka [1992], B resnahan and Salop [1986], Reynolds and Snapp [1986]). The new producing entity operates independently with the superior technology while its parent firms are competing with their original technologies. Profits of the venture firm are shared by both the foreign and local firms entering the contract.

In all the above agreements we assume that the strength of bargaining power lies with the foreign firm. Hence, it extracts all the surplus resulting from the collaborating deal, leaving the collaborating domestic firm with its non-cooperative reservation payoff.

Our purpose is to find the optimal collaboration deal from the perspective of domestic welfare. As we show, depending on the degree of cost asymmetry it is al ways profitable for the foreign firm to go for the one or the other deal; hence our problem is to study which contract or contracts are to be allowed by the local government to maximize domestic welfare. We have a 
two-stage game where in the first stage the local government takes note of the profitable agreements from the viewpoint of the foreign firm and accordingly asks the foreign firm to form a collaboration which maximizes the sum of consumers' surplus and producers' surplus remaining in the domestic country. So in the second stage the foreign firm either accepts the welfaremaximizing agreement for expansion or else it decides to stay non-cooperative $(\mathrm{N})$. We solve for sub-game perfect $\mathrm{N}$ ash equilibrium of this game by the method of backward induction.

The general result that follows from our analysis is that, while depending on the initial degree of cost asymmetry, the foreign firm may want to choose either a licensing deal, merger or a joint venture, the local government will generally encourage a new firm joint venture agreement. It is seen that the foreign firm always prefers to expand its profit via some collaboration, rather than to stay non-cooperative, but due to the conflict of objectives between the social planner and the firm, there may be equilibrium situations where the government may not allow any collaboration or may prevent a particular form of collaboration.

B efore we go to the next section let us provide a discussion on empirical issues related to the different forms of collaborative agreements. Such collaborations between multinationals and local firms are clearly visible in less developed countries like India. For example, there had been a tremendous increase in the number of technological collaborations between foreign multinationals and Indian firms during the 80 's. This is quite evident from the RBI survey on foreign collaborations (First to Fourth Survey, [196885]). One may also look at a host of articles in the Economic and Political Weekly, Special Number [1985]. These works, based on the case studies, examine the contractual and policy issues. Bagchi [1987] and M arjit and Singh [1995] provide analysis on the related issues. The merger activities are also growing in importance since the beginning of the 80's in India and elsewhere. Roy [1995] has exemplified mergers between foreign sub-

1. The feasibility of each deal is independent of this assumption but the welfare implications will be different under some other assumption of the bargaining strength. Given that all the local firms are identical, our assumption that the foreign firm takes all the surplus seems justified if we consider a bidding game. 
sidiaries and Indian firms. In the context of trade liberalization the increased merger and acquisition activity has been documented, among others, by J acquemine [1990] and Globerman [1990].

The most important visible collaborative form of business organization as we experience in the post-liberalization period in the developing countries is joint venture. In our paper the joint venture firm competes with the fullyowned subsidiaries of the parent firms. K woka [1992] calls this form a new firm joint venture. Although examples of this form of joint venture are not many, but not rare. Profit extraction through creating competition is one of the reasons why the firms may prefer this type of joint venture formation. Recently Zhao [1997] provides a political-economy approach to the formation of joint ventures. Zhao cites cases of J apanese-US joint ventures which are similar to our structure.

The next section provides the model and the results. The last section concludes the paper. The proofs of all the propositions are provided in the appendix.

\section{Model}

We consider an initial $(m+1)$ firms oligopoly industry of a homogeous good in the domestic market. We assume that out of these $m+1$ firms, $m$ are domestic firms which are technologically backward, $m \geq 2$. The other firm is a technologically advanced firm which is a subsidiary of a foreign based M NC which has full holding of the subsidiary. The firms compete in quantities like Cournot oligopolists. The market demand function is assumed to be linear and in inverse form. It is given by:

$$
p=-\sum_{i=1}^{m+1} q_{i}
$$

where, $p$ is the price of the product and $q_{i}$ is the demand for the $i^{\text {th }}$ firm's product.

The production technology is represented by a constant marginal cost

2. We have assumed $m \geq 2$ so that even without the foreign firm the local market is an oligopoly. 
(mc henceforth) and there is no other cost of production. The mc of production by the foreign firm is $c_{1}$ and that of each of the domestic firms is $c_{;} c_{1}<c$ $<\alpha$.

We discuss the possibility of bilateral technology transfer agreement, merger and joint venture between the foreign firm and a domestic firm. Let $a$ be the foreign firm and $b_{i}$ be the $i^{i \text { th }}$ domestic firm, $i=1,2, \ldots, m$, to which a offers one of the three collaborative agreements ${ }^{3}$. The offer can either be accepted or rejected by $b_{i}$. Firm $b_{i}$ will accept the offer if it is better off than in non-cooperation. In our model $b_{i}$ can not exercise any other power in the enforcement of the deal.

Under technology transfer we consider a fixed fee contract where a transfers its superior technology $c_{1}$ to $b_{i}$ and charges a lumpsum fee, and after technology transfer both the buyer and the seller compete in the same domestic market ${ }^{4}$. But under bilateral merger, the merging firms reduce to a single entity, giving up their individual entities forever, which will be producing at an $\mathrm{mc}, \mathrm{c}_{1}$. Thus there is a reduction in the number of firms in the market. But in the case of a joint venture, a new firm is created by the contract between $a$ and $b_{i}$ and thereby there are two firms having the advanced technology in the market whereas the number of domestic firms remains unchanged. Thus the number of firms will be increased as a result of this type of joint ventures.

Let $\Pi_{k}^{s}$ denote the $k^{\text {th }}$ firm's payoff under state $s$ where $s=N, T, M, J ; k=$ $b_{i}, a, n ; i=1,2, \ldots, m$; and $n$ is the new firm formed under joint venture.

The sum of the payoffs of firms a and bi under state $s$ is denoted by $\Pi_{s^{\prime}}$ i.e.

$$
{ }^{s}={ }_{a}^{s}+{ }^{s} b_{i}
$$

where $\mathrm{s}=\mathrm{N}, \mathrm{T}, \mathrm{M}$, but under $\mathrm{J}$,

$$
{ }^{J}={ }_{a}^{J}+{ }_{b_{i}}^{J}+{ }_{n}^{J} .
$$

It may be noted that under $\mathrm{M}$, we are concerned about $\Pi^{\mathrm{M}}$ only, and not

3. As all the backward firms are similar, the deal can be formed by a with any $b_{i}, i=1,2$, ..., $\mathrm{m}$.

4. This is a situation where technology is costlessly imitable and a royalty deal is not optimal (see Rockett [1990]). 
its distribution.

We assume $c_{1}<c<\bar{c}$ where,

$$
\bar{c}=\frac{\left(+c_{l}\right)}{2}
$$

Given equation (2.1) the above assumption ensures an initial oligopolistic structure consisting of $m+1$ firms 5 .

In initial situation the payoffs are given by $\Pi_{a}^{N}=$ and $\Pi_{b_{1}}^{N}=\frac{\left(-2 c+c_{1}\right)^{2}}{(m+2)^{2}}$. So the sum of the two firms under non-cooperation is given by:

$$
\Pi^{\mathrm{N}}=\Pi_{\mathrm{a}}^{\mathrm{N}}+\Pi_{\mathrm{b}_{1}}^{\mathrm{N}}=\frac{\left(-(m+1) c_{l}+m c\right)^{2}+\left(-2 c+c_{l}\right)^{\frac{\left(-(m+1) c_{l}+m c\right)^{2}}{2(2)^{2}}}}{(m+2)^{2}}
$$

\section{A. Technology Transfer}

A technology transfer agreement between firms a and bi is profitable under fixed fee contract iff the sum of their post-transfer payoffs is larger than that in the pre-transfer situation, i.e., ${ }_{a}^{T}+{ }_{b_{i}}^{T}>{ }_{a}^{N}+{ }_{b_{i}}^{N}$ or,

${ }^{T}>{ }^{N}$

Given equation (2.1) we get

$$
T= \begin{cases}\frac{2\left(-m c_{l}+(m-1) c\right)^{2}}{(m+2)^{2}}, & \forall c \in\left(c_{l}, c^{*}\right) \\ \frac{2\left(-c_{l}\right)^{2}}{9} & , \quad \forall c \in\left[c^{*}, \bar{c}\right)\end{cases}
$$

where

$$
c^{*}=\frac{+2 c_{l}}{3}<\bar{c}
$$

5. With one foreign and $m$ domestic firms the local government does not allow the subsidiary if its entry in the local market sends all the domestic firms out of the market. Thus the foreign firm is not allowed if the market reduces into the foreign firm's monopoly, i.e., if $c>p_{m}\left(C_{l}\right)$ i.e., if $c>\frac{\left(+c_{l}\right)}{2}$ 
$\Pi^{\top}$ is convex and non-decreasing in c with $\Pi^{\top}$ strictly increasing over $c \in$ $\left(c_{1}, c^{*}\right)$ and constant for $c \in\left[c^{*}, \bar{c}\right)$.

The above results follow from the fact that relative to the advanced technology, the backward technology is such that if it is above a critical level (i.e. if $c \geq c^{*}$, i.e. if $c \geq p_{d}\left(c_{1}\right)$, where $p_{d}\left(c_{1}\right)$ is the duopoly price under technology $c_{1}$ ), in the post-transfer situation all the firms competing with backward technology cease to operate, and hence $\Pi^{\top}$ for $c \in\left(c^{*}, \bar{c}\right)$ gives the duopoly collaborating profits whence the two firms under agreement only exist in the market. However, if the backward technology is not that backward $\left(c<c^{*}\right)$, all $m+1$ firms will exist in the market and this is given by $\Pi^{\top}$ for $c$ $\in\left(c_{1}, c^{*}\right)$ showing the collaborating profits of the two firms under the licensing agreement.

It should be noted that $c^{*}$ is independent of $m$, the number of backward firms. This implies that the firms possessing backward technology cease to operate together given that the backward firms have identical technologies; naturally when one such firm finds its operation unprofitable, all the other backward firms' operation also becomes unprofitable.

Proposition 2.1: $\exists c_{t}, c^{*}<c_{t}<\bar{c}$ such that $\forall c \in\left(c_{1}, c_{t}\right)$ a technology transfer deal is profitable.

If the asymmetry in costs between the advanced firm and the backward firm is low, then a technology transfer deal is profitable. With very high degree of cost asymmetry the low cost foreign firm is nearly a monopoly, and therefore technology transfer will create competition large enough to reduce joint profits. Thus there exists $c_{t}$ close to $\bar{c}$, whereafter technology transfer deal is not profitable due to the existence of duopoly market for $c_{t}>c^{*}$ and $c_{t}<$ $\bar{c}$. Hence breaking up of the oligopoly structure into a duopoly of the collaborating firm is a necessary condition for not having a profitable technology transfer. Thus $\forall c \in\left[c_{t}, \bar{c}\right)$ is an infeasible zone of technology transfer. 


\section{B. Merger}

Now consider the possibility of merger between firms $a$ and $b_{i}$. We define a merger between $a$ and $b_{1}$ to be profitable iff $\Pi^{\mathrm{M}}>\Pi^{\mathrm{N}}$, where $\Pi^{\mathrm{M}}$ is the merged firm's payoff.

$$
\Pi^{\mathrm{M}}=\frac{\left(-m c_{l}+(m-1) c\right)^{2}}{(m+1)^{2}}
$$

$\Pi^{\mathrm{M}}$ is convex and increasing in c (as $m \geq 2$ ).

Proposition 2.2: $\exists c_{m}$ such that $\forall c \in\left(c_{m}, \bar{c}\right)$ merger between firms a and $b$ is profitable.

It states that if the asymmetry in costs between the advanced and the backward firm is not large then the merger is not profitable. But for high cost asymmetry bilateral merger is profitable. In this model merger increases concentration by dropping inefficient firms. But still bilateral merger is not profitable if $m>1$ (Salant et al, [1983]), because any effort to concentrate market power through merger by reducing output of the merged firm is offset by the induced expansion of the rivals' output outside the merger making merger unprofitable. Only if cost reduction is sufficiently large, merger becomes unprofitable for the constituent firms (Long and Vousdon[1995] and Perry and Porter[1985]). ${ }^{6}$

\section{J oint Venture}

Lastly we consider the possibility of a joint venture between the firms a and $b_{i}$. However this collaboration is different in the sense that a new firm $n$ is formed. This new firm is also competing in the market along with the existing $m+1$ firms and it has an $m c_{,} c_{1}$. The domestic firm $b_{i}$ entering the deal is still operating with its backward technology $c$, if it is profitable.

The joint venture deal between $a$ and $b_{i}$ is defined to be profitable iff $\Pi_{a}^{J}+$

6. The above analysis of technology transfer and merger is mostly borrowed from $\mathrm{M}$ arjit, Kabiraj and M ukherjee[1996] 
$\Pi_{b_{i}}+\Pi_{n}^{j}>\Pi_{a}^{N}+\Pi_{b_{i}}^{N}$, or, $\Pi^{J}>\Pi^{N}$, where $\Pi_{n}^{j}$ is the profit of the new firm formed under joint venture and this profit is shared by the collaborating firms by some fixed rules. Again $\Pi^{1}$ is the profit of the collaborating firms under joint venture.

$$
\Pi^{J}= \begin{cases}\frac{2\left(-(m+1) c_{l}+m c\right)^{2}}{(m+3)^{2}}+\frac{\left(-3 c+2 c_{l}\right)^{2}}{(m+3)^{2}}, & \forall c \in\left(c_{l}, c^{*}\right) \\ \frac{2\left(-c_{l}\right)^{2}}{9}, & \forall c \in\left[c^{*}, \bar{c}\right),\end{cases}
$$

where $c^{*}=\frac{+2 c_{l}}{3}$. Again, $\Pi^{J}$ is convex and non-decreasing in $c$, with $\Pi^{J}$ strictly increasing over $c \in\left(c_{1}, c^{*}\right)$ and constant for $c \in\left[c^{*}, \bar{c}\right)$.

The result in the above equation can be interpreted as follows: if the backward technology is so backward that all the backward firms have an mc above $c^{*}$, the critical per unit cost, then other than the two advanced firms ( $n$ and $a$ ), all other backward firms cease to exist. Even the domestic firm entering the deal of joint venture shuts down its backward plant and survives on the profits extracted from the new firm $n$. However, if the per unit cost of the domestic firm is lower than $c^{*}$, the $m+2$ firms exist in the market, and $\Pi^{j}$ for $c \in\left(c_{1}, c^{*}\right)$ is the sum of collaborating profits of the three firms participating in joint venture in the above case.

Now, this critical cost level $c^{*}$ is the same as in equation (2.6) under technology transfer, because if the cost is higher than $c^{*}$, there are only two firms in the market in both $J$ and $T$ regimes. Thereby, $\Pi^{J}$ and $\Pi^{\top}$ for $c \in\left[c^{*}\right.$, $\bar{c})$ gives the same joint profit in the duopoly market.

Proposition 2.3: If $m=2$, then $\exists c_{j}, c_{l}<c_{j}<c^{*}$ such that $\forall c \in\left(c_{j}, c_{t}\right)$, a joint venture deal is profitable, and if $m \geq 3$, then $\forall c \in\left(c_{1}, c_{t}\right)$, a joint venture deal is always profitable.

If the technology difference between the advanced firm and the backward firm is very high, then a joint venture deal is not profitable, irrespective of the number of firms in the market. This is so because in such a case, the advanced firm is nearly a monopoly and would prefer near monopoly profits rather than the profits drawn in a duopoly situation due to joint venture deal. Thus, there exists a $c_{t}$ (same as in technology transfer), close to $\bar{c}$, after 
which the joint venture deal is not profitable. Again, as a result of a new efficient firm in the market, profitability of the firm increases. The concentration of the market decreases, increasing the competition in the market, thereby reducing individual output and profit. Usually there being many firms, the individual loss due to the increase in the number of firms is offset by the efficiency gain - making the joint venture profitable. If however the efficiency gain is not much and the number of firms in the market is less, then the loss of profit due to decrease in concentration outweighs all other effects and thereby makes the joint venture unprofitable. Now we study the relative profitability of the three alternative bilateral agreements. Using the above propositions we deduce the following result.

Corollary 2.1: If $m=2$, then (1) $\exists c \in\left(c_{1}, c_{j}\right)$, where only technology transfer is profitable, (2) $\exists c \in\left(c_{j}, c_{m}\right)$, where technology transfer and joint venture are profitable but not merger ${ }^{7},(3) \exists c \in\left(c_{m}, c_{t}\right)$, where all the three collabo ration modes are profitable, (4) $\exists c \in\left(c_{t}, \bar{c}\right)$, where only merger is prof itable. However if $m \geq 3$, then (1) $\exists c \in\left(c_{1}, c_{m}\right)$, where technology transfer and joint venture are profitable, (2) $\exists c \in\left(c_{m}, c_{t}\right)$, where technology trans fer, merger and joint venture are all profitable, (3) $\exists c \in\left(c_{t}, \bar{c}\right)$, where only merger is profitable.

The above results are shown in Figures 1 and 2.

\section{Profit-Maximizing Collaboration of the Foreign Firm}

From the above corollary we are now in a position to conclude the optimal (i.e. profit-maximizing) choice of the collaboration form of the foreign firm when the local government has no-intervention policy. First of all note that for any cost situation of the backward firm, the M NC has at least one form of the collaboration which is profitable to go for, and hence the M NC first finds the profitable options available to it. This is shown in column 2 of tables 1 and 2 . Then out of the available options it will choose the one which 7. Using M arjit, Kabiraj and M ukherjee [1996] result, $c_{m}=\frac{\left(-c_{l}\right)[(m-1)(m+1)-1]}{(2 m+3) 2 m}$,
for $m=2$ we can show that at $c_{m}, \Pi^{J}>\Pi^{N}$ and hence $c_{m}>c_{j}$. 
gives him maximum profit. This is given in column 3 of the tables. Hence we have following propositions.

Proposition 2.4: Suppose there is no intervention policy of the local govern ment. Then:

(1) If $m=2$, then $\forall c \in\left(c, c^{*}\right)$, technology transfer is most profitable for the foreign firm. Again, $\exists c^{1}, c^{*}<c^{1}<c_{t}$ such that $\forall c \in\left[c^{*}, c^{1}\right)$, joint venture and technology transfer are equally the most profitable options and $\forall c \in\left(c^{1}, \bar{c}\right)$, merger is the most profitable option.

(2) If $m \geq 3$, then, $\exists c^{2}, c_{t}<c^{2}<c_{m}$, such that $\forall c \in\left(c_{1}, c^{2}\right)$, joint venture is the best option for the MNC and $\forall c \in\left(c^{2}, c^{*}\right)$, technology transfer gives the maximum profit. Again, $\exists \widehat{C}, c^{*}<\widehat{C}<c_{t}$, such that $\forall c \in\left(c^{*}, \widehat{C}\right)$, joint venture and technology transfer are equally good and $\forall c \in(\widehat{c}, \bar{c})$, merger is most prof itable.

It follows that the cost asymmetry between the advanced and the backward firms plays a vital role in determining the collaboration technique of the foreign firm if collaboration is profitable. If there are only few domestic firms and a very low cost differential exists, then technology transfer is the best option for the M NC. However if the cost asymmetry is higher, (so that all the backward firms leave the market), then joint venture and technology transfer are equally profitable. But if the initial cost difference is such that a near monopoly of the MNC, it will be profitable for it to go for a merger.

However, if there is an oligopolistic structure in the domestic market with a large number of firms, then for a lower cost differential, a joint venture is most profitable. If the cost differential is higher, licensing gives the maximum profit. Again, if all the backward firms leave the market, then licensing and joint venture are equally profitable. And lastly, in case of a near monopoly of the foreign firm, merger is the best option.

Thus we observe that in the absence of intervention by the local government, in no case does the foreign firm decide to stay non-cooperative and would rather prefer collaboration of some form to increase its profits. 


\section{E. Welfare Analysis}

So far we have discussed the outcome of the second stage game and now we are concerned with the first stage problem, viz., the domestic welfare maximization. Hence our problem is to find out the optimal form of collaboration to be allowed by the local government, given the optimal behavior of the foreign firm. The government observes all the profitable collaboration modes of the foreign firm and then dictates the foreign firm to accept the mode which is welfare maximizing. Obviously, it may not be the best for the foreign M NC. It is also possible in equilibrium that no collaboration occurs.

In our analysis domestic welfare consists of consumer surplus and profits of the local firms. We assume that the full profit of the foreign firm is extracted away from the country, and there is no tax-subsidy policy of the local government. We also assume that the foreign firm has all the bargaining power in any agreement so that the whole surplus is taken away by the foreign firm, leaving the local firm only with what it earns under non-cooperation situation.

Let $W^{s}$ denote the welfare of the domestic country under state $s$, where $s$ $=N, T, J$ or $M$. Then, $W^{s}=(C S)^{s}+(P S)^{s}$, where $(C S)^{s}$ is the consumers' surplus under state $s$ and $(P S)^{s}$ is the producers' surplus under state $s$ which is actually the profit of the local firms staying back in the country. Given the demand function as in equation (2.1) the consumers' surplus under state $s$ is given by $(C S)^{s}=0.5 q_{s}^{2}$ where $q_{s}$ is the industry output under state $s$.

Under non-cooperation there are $m$ domestic firms in the market and profits of the $\mathrm{m}$ firms form the producers' surplus. Thus the initial welfare is given by,

$$
W^{N}=\frac{\left((m+1)-m c-c_{l}\right)^{2}}{2(m+2)^{2}}+\frac{m\left(-2 c+c_{l}\right)^{2}}{(m+2)^{2}}
$$

where $\mathrm{W}^{\mathrm{N}}$ is declining and convex in $\mathrm{C}$.

In case of technology transfer, there are $m$ domestic firms of which $m$--1 are backward firms and one is an advanced firm. But this advanced firm's excess profit is extracted by a lump-sum fee, such that it is left with only the non-cooperative profit. Thus the welfare under regime $T$ is given by: 


$$
W^{T}=\left\{\begin{array}{l}
\frac{\left((m+1)-(m-1) c-2 c_{l}\right)^{2}}{2(m+2)^{2}}+\frac{(m-1)\left(-3 c-2 c_{l}\right)^{2}}{(m+2)^{2}}+\frac{\left(-2 c+c_{l}\right)^{2}}{(m+2)^{2}}, \forall c \in\left(c_{l}, c^{*}\right) \\
\frac{2\left(-c_{l}\right)^{2}}{9}+\frac{\left(-2 c+c_{l}\right)^{2}}{(m+2)^{2}}, \forall c \in\left[c_{l}, c^{*}\right)
\end{array}\right.
$$

The above equation gives the welfare in the $m+1$ market structure and duopoly market structure respectively in the technology transfer case.

Proposition 2.5: For $m=2, \exists c_{w}^{1}, c_{1}<c_{w}^{1}<c^{*}$ such that $\forall c \in\left(c_{w}^{1}, c_{t}\right)$, technol ogy transfer gives more welfare than noncooperation. However, for $m \geq 3$, $\forall c \in\left(c_{1}, c_{t}\right)$, technology transfer is welfare increasing.

In case of a technology transfer, there is a transformation of a backward firm into an efficient firm. So if there are large number of firms in the market, the efficiency gain is always welfare increasing. However if the efficiency gain is not much in case of small number of firms, the loss of profits of the non-collaborating backward firms becomes dominant and outweighs the efficiency gain. Thus the resultant effect may be welfare decreasing.

We have already noted that a merger is profitable over $\forall c \in\left(c_{m}, \bar{c}\right)$, and hence the welfare over this range.

$$
\mathrm{W}^{\mathrm{M}}=\frac{\left.(m-1)-(m-1) c-c_{l}\right)^{2}}{2(m+1)^{2}}+\frac{(m-1)\left(-2 c+c_{l}\right)^{2}}{(m+1)^{2}}+\frac{\left(-2 c+c_{l}\right)^{2}}{(m+2)^{2}}
$$

$\mathrm{W}^{\mathrm{M}}$ is quadratic, decreasing, continuous and convex in $\mathrm{C}$.

Proposition 2.6: For $m<4, \forall c \in\left(c_{m}, \bar{c}\right)$, the welfare under non-cooperation is more than the welfare under merger. For $m \geq 4, \exists c_{w}, c_{m}<c_{w}<c^{*}$, such that $\forall c \in\left(c_{m}, c_{w}\right)$ a merger gives more welfare than in non-cooperation and $\forall \mathrm{c} \in\left(\mathrm{c}_{\mathrm{w}}, \overline{\mathrm{c}}\right)$, non-cooperative structure gives more welfare than in merger.

The new firm under merger will typically reduce its output below the combined output of its constituent firms. As a result, industry price should increase if the cost reduction is not high. But the non-participants will then expand their output and profit at higher industry price. Thus for the case of many firms and lower cost differential, the welfare increases. This does not 
work for a few firms. And for higher cost differential the increased profit of the merging firms is large and is extracted abroad thereby reducing welfare in the host country.

A joint venture is profitable $\forall c \in\left(c_{1}, c_{t}\right)$. Hence the welfare configuration under joint venture is given by:

$$
W^{J}= \begin{cases}\frac{\left((m+2)-m c-2 c_{l}\right)^{2}}{2 m+3)^{2}}+\frac{m\left(-3 c+2 c_{l}\right)^{2}}{(m+3)^{2}}+\frac{\left(-2 c+c_{l}\right)^{2}}{(m+2)^{2}}, & \forall c \in\left(c_{l}, c^{*}\right) \\ \frac{2\left(-c_{l}\right)^{2}}{9}+\frac{\left(-2 c+c_{l}\right)^{2}}{(m+2)^{2}}, & \forall c \in\left[c_{l}, c^{*}\right)\end{cases}
$$

The above equation gives the welfare under joint venture respectively in the $m+2$ firms and two firm market structure.

Proposition 2.7: For $m=2, \forall c \in\left(c_{j}, c_{t}\right)$, a joint venture deal is welfare increasing. However, for $m \geq 3, \forall c \in\left(c_{1}, c_{t}\right)$, a joint venture gives more welfare than in non-cooperation.

In our case joint venture implies an addition of a new efficient firm in the market. So efficiency increases and market concentration falls. This results in an increase in industry output sufficiently which thereby increases domestic welfare.

Corollary 2.2: For $m=2, \exists c \in\left(c_{1}, c_{j}\right)$, maximum welfare is attained under non- cooperative structure; $\exists c \in\left(c_{j}, c_{w}^{1}\right)$, only joint venture gives more wel fare than non-cooperation ${ }^{8} ; \exists c \in\left(c_{w}^{1}, c_{t}\right)$, both technology transfer and joint venture are welfare increasing; $\exists c \in\left(c_{t}, \bar{c}\right)$, where non cooperation is the only alternative. For $m=3, \exists c \in\left(c_{1}, c_{t}\right)$, where both joint venture and tech nology transfer are both welfare increasing; $\exists c \in\left(c_{t}, \bar{c}\right)$, where non cooper ation persists. For $m \geq 4, \exists c \in\left(c_{1}, c_{m}\right)$ where both joint venture and tech nology transfer generate more welfare; $\exists c \in\left(c_{m}, c_{w}\right)$ where joint venture, merger and technology transfer are all welfare increasing; $\exists c \in\left(c_{w}, c_{t}\right)$ where again only joint venture and licensing are give larger welfare; $\exists c \in$ $\left(c_{t}, \bar{c}\right)$, where non cooperation is a better choice in terms of welfare.

8. $c_{m}<c_{w}^{1}<c^{*}$. Now $W^{\top}>W^{N}$ at $c_{m}$, and hence $c_{w}^{1}>c_{m}$. 
The above results are clear in Figures 1 and 2 . Now we consider the action of the social planner who maximizes welfare over the profitable alternatives of collaboration and draw the final result:

Table 1

In the Case of $\boldsymbol{m}=\mathbf{2}$

\begin{tabular}{|l|c|c|c|}
\hline $\begin{array}{c}\text { Cost of } \\
\text { Backward Firms }\end{array}$ & Profitable Options & $\begin{array}{c}\text { Most Profitable } \\
\text { Option }\end{array}$ & $\begin{array}{c}\text { Welfare } \\
\text { M aximizing Option }\end{array}$ \\
\hline$\forall c \in\left(c_{1}, c_{\mathrm{j}}\right)$ & $\mathrm{T}$ & $\mathrm{T}$ & $\mathrm{N}$ \\
$\forall c \in\left(c_{\mathrm{j}}, c_{\mathrm{m}}\right)$ & $\mathrm{T}, \mathrm{J}$ & $\mathrm{T}$ & $\mathrm{J}$ \\
$\forall c \in\left(c_{\mathrm{m}}, c^{*}\right)$ & $\mathrm{T}, \mathrm{J}, \mathrm{M}$ & $\mathrm{T}$ & $\mathrm{J}$ \\
$\forall c \in\left(c^{*}, c^{1}\right)$ & $\mathrm{T}, \mathrm{J}, \mathrm{M}$ & $\mathrm{T}, \mathrm{J}$ & $\mathrm{T}, \mathrm{J}$ \\
$\forall c \in\left(c^{1}, c_{\mathrm{t}}\right)$ & $\mathrm{T}, \mathrm{J}, \mathrm{M}$ & $\mathrm{M}$ & $\mathrm{T}, \mathrm{J}$ \\
$\forall c \in\left(c_{\mathrm{t}}, \bar{c}\right)$ & $\mathrm{M}$ & $\mathrm{M}$ & $\mathrm{N}$ \\
\hline
\end{tabular}

Figure 1
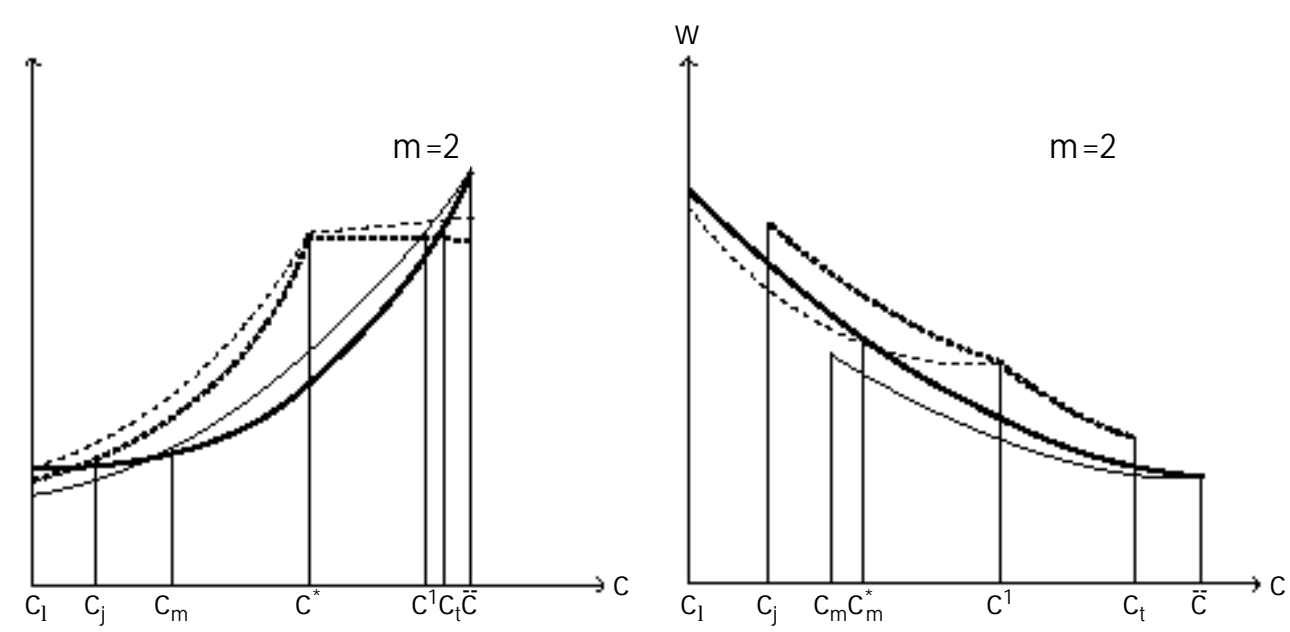

Notes; $N:-, T:-----, ~ J:---, M:$ 
Table 2

In the Case of $m \geq 3$

\begin{tabular}{|l|c|c|c|}
\hline $\begin{array}{c}\text { Cost of } \\
\text { Backward Firms }\end{array}$ & Profitable Options & $\begin{array}{c}\text { M ost Profitable } \\
\text { Option }\end{array}$ & $\begin{array}{c}\text { Welfare } \\
\text { M aximizing Option }\end{array}$ \\
\hline$\forall c \in\left(c_{1}, c^{2}\right)$ & $\mathrm{T}, \mathrm{J}$ & $\mathrm{J}$ & $\mathrm{J}$ \\
$\forall c \in\left(c^{2}, c_{m}\right)$ & $\mathrm{T}, \mathrm{J}$ & $\mathrm{T}$ & $\mathrm{J}$ \\
$\forall c \in\left(c_{\mathrm{m}}, c^{*}\right)$ & $\mathrm{T}, \mathrm{J}, \mathrm{M}$ & $\mathrm{T}$ & $\mathrm{J}$ \\
$\forall c \in\left(c^{*}, \hat{\mathrm{C}}\right)$ & $\mathrm{T}, \mathrm{J}, \mathrm{M}$ & $\mathrm{T}, \mathrm{J}$ & $\mathrm{T}, \mathrm{J}$ \\
$\forall c \in\left(\hat{c}_{\mathrm{c}}\right)$ & $\mathrm{T}, \mathrm{J}, \mathrm{M}$ & $\mathrm{M}$ & $\mathrm{T}, \mathrm{J}$ \\
$\forall c \in\left(c_{\mathrm{t}}, \overline{\mathrm{C}}\right)$ & $\mathrm{M}$ & $\mathrm{M}$ & $\mathrm{N}$ \\
\hline
\end{tabular}

Figure 2
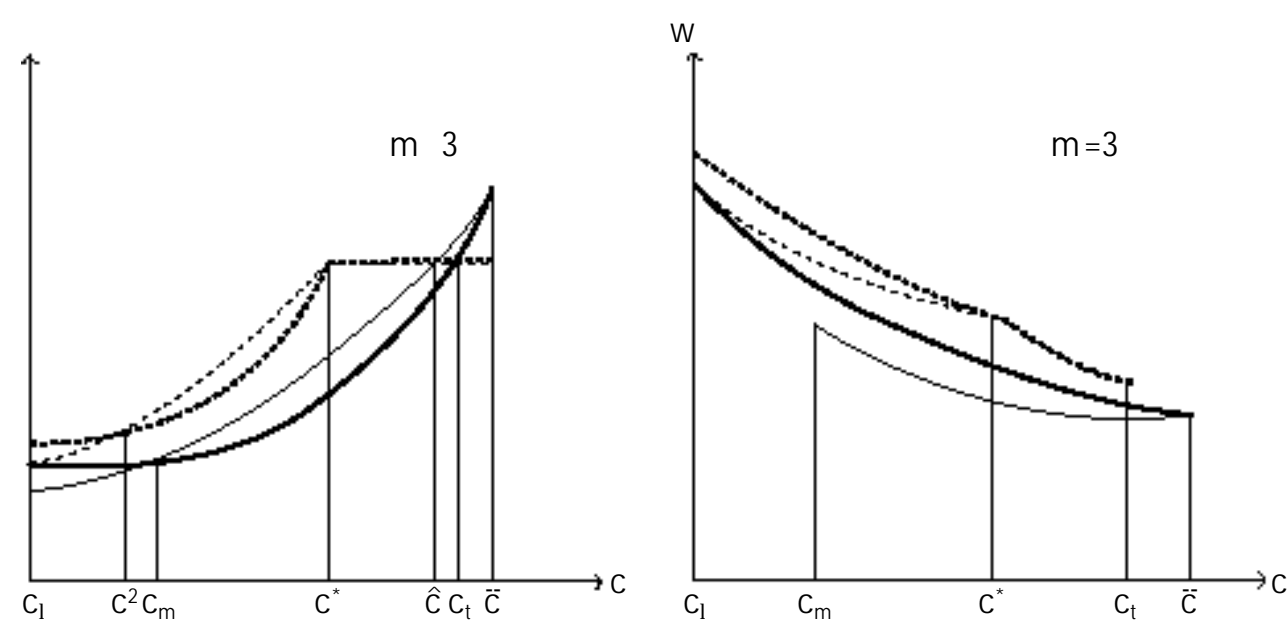

Notes; $\mathrm{N}:-, \mathrm{T}:-\cdots$,

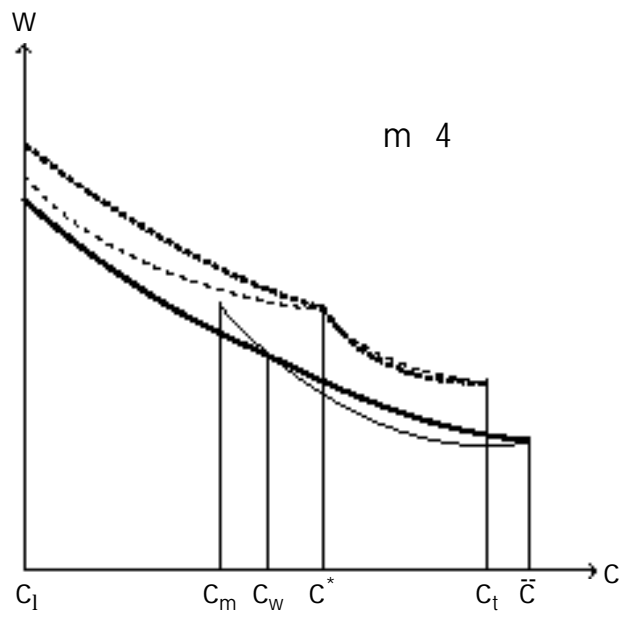


Proposition 2.8: F or $m=2, \exists c \in\left(c_{1}, c_{j}\right)$, where no collaboration is possible; $\exists c \in\left(c_{1}, c^{*}\right)$, where joint venture is welfare maximizing; $\exists c \in\left[c^{*}, c_{t}\right)$, where both joint venture and technology transfer are welfare maximizing; $\exists c \in$ $\left[c_{t}, \bar{c}\right)$, where again non cooperation gives the maximum welfare. For $m \geq$ $3, \exists c \in\left(c_{1}, c^{*}\right)$, where joint venture is welfare maximizing; $\exists c \in\left[c^{*}, c_{t}\right)$, where both joint venture and technology transfer are welfare maximizing; $\exists c \in\left[c_{t}, \bar{c}\right)$, where again non cooperation gives the maximum welfare.

The results of the above proposition are summarized in column 4 of tables 1 and 2 . The above proposition throws light on the scope of some policy intervention of the local government. If there is a conflict of objectives between the government and the M NC, the government can simply disallow one particular mode of collaboration which directly results into the welfare maximizing collaboration deal. If $m=2, \forall c \in\left(c_{1}, c_{m}\right)$, the government does not allow technology transfer deal. This leads to noncoperation $\forall c \in$ $\left(c_{1}, c_{j}\right)$ and joint venture $\forall c \in\left(c_{j}, c^{*}\right)$. If $m \geq 3, \forall c \in\left(c_{1}, c^{2}\right)$, the government does not interfere and the M NC opts for joint venture. Again for $m \geq 3, \forall c \in$ $\left(c^{2}, c^{*}\right)$ the government intervenes to disallow technology transfer. This will again result into a joint venture formation. Now irrespective of the number of firms, $\forall c \in\left(c^{*}, c_{t}\right)$ the government allows the MNC to pick its profit maximizing option, that is either technology transfer or joint venture. But $\forall c \in$ $\left(c_{t}, \bar{C}\right)$ government prevents the formation of a merger which result into non-cooperation. All the options thereby chosen by the foreign firm after government inter vention are welfare maximizing for the local country.

\section{Conclusion}

We have considered the scenario where there is an oligopolistic domestic market with some local firms and an M NC subsidiary. The foreign firm has superior technology and the local firms have identical backward technology. In our analysis the initial cost differential or asymmetry in technology between the foreign and domestic firms play the most important role. Over some range of cost asymmetry, the local government and the foreign M NC have conflicting interests, but over some other range they have mutually consistent interests.- In a near monopoly situation of the foreign firm, it 
wants to merge with a local firm to increase profit. But the government does not allow any such collaboration. Again if the cost differential is so large that either after licensing or joint venture the market breaks down into a duopoly of the collaborating firms, these firms prefer joint venture and licensing equally, and the social planner allows them to go for both options. However, assuming large number of domestic firms, if the cost difference is very small, the firms and the government both agree to a joint venture. But for a sufficiently large cost difference the most profitable mode of collaboration is licensing. But still a joint venture is formed as per government restrictions. Assuming a few firms in the market and low cost difference, the government does not allow any expansion of the foreign firm, although it is profitable for the firm to go for licensing. For a higher cost difference, there being a conflict in objectives for the M NC and the government, a joint venture agreement is formed even though the firm prefers technology transfer more. Thus an LDC should usually encourage the expansion of an M NC through a joint venture with a local firm creating a new firm in the market.

In this particular paper certain assumptions are made which can be relaxed in future analysis. We have assumed the bargaining strength to be fully in M NC's hands. Other bargaining processes can also be used. In that case the extraction of profits outside the domestic country will be less. This would surely increase the home producers' surplus in all cases. While the feasibility zones of each deal will remain unchanged, however the optimal choice may be changed. We have considered only bilateral agreements in this paper, which does not take care of multiple licensing being a possible collaboration technique. Another possibility is that of a technology transfer even after the deal of joint venture. The feasibility of such a contract has also not been checked. In our analysis the existence of a foreign M NC is assumed to be historically given. However the prior entry decision may be strategic.

So one natural extension should be to examine the question of entry of new foreign firms. Will the local government allow unconditional entry or entry only through forming some collaborating arrangements with the local firms? The local government may favor this policy because through a collaborative arrangement the local firms might get an access to better technologies and foreign markets. Consumers might benefit from the possible lowering prices. 


\section{References}

Bagchi, A. K. [1987], Public Intervention and Industrial Restructuring in China, India and Republic of Korea, ARTEP, ILO, New Delhi.

Baranson, J. [1978], Technology and the Multinationals: Corporate Strategies in a Changing World Economy, Lexington, MA: Lexington Books, D.C.Heath.

Bardhan, P. K. [1982], "Imports, Domestic Production, and Transnational Vertical Integration: A Theoretical N ote," Journal of Political E conomy 90; pp. 1020-34.

B resnahan, T and Salop, S [1986], "Quantifying the Competitive Effects of Production J oint Ventures," International Journal of Industrial Organi zation 4; pp. 155-175.

Caves, R. [1971], "International Corporations: the Industrial Economics of Foreign Investment," Economica 38; pp. 1-27.

Caves, R. [1982], Multinational Enterprise and Economic Analysis, Cambridge: Cambridge University Press.

Globerman, S. [1990], "Trade Liberalization and Competitive Behavior: A Note Assessing the Evidence and Public Policy Implications," Journal of Policy Analysis and M anagement 9; pp. 80-88.

J acquemin, A. [1990], "Horizontal Concentration and European M erger Policy," European Economic Review 34; pp. 539-50.

Kabiraj, T. [1993], "Tariffs Versus Licensing in the Presence of Fixed Costs," Journal of International Trade and E conomic Development 2.

Katz, M. and Shapiro, C. [1985], "On the Licensing of Innovations," Rand Journal of Economics 16; pp. 504-519.

Kwoka, J. E. [1992], "The Output and Profit Effects of Horizontal J oint Ventures," Journal of Industrial E conomics 40; pp. 325-338.

Long, N. V. and Vousden, N. [1995], "The Effects of Trade Liberalization on Cost Reducing M ergers," Review of International Economics 3; pp. 141155.

M arjit, S. [1990], "On a Non-Cooperative Theory of Technology Transfer," E conomics Letters 33; pp. 293-298. 21

M arjit, S., Kabiraj, T. and M ukherjee, A.[1999], "Bilateral Agreements in a Multifirm Industry: Technology Transfer and Horizontal Merger," 
Pacific E conomic Review (for thcoming)

M arjit, S. and Singh, N. [1995], "Technology and Indian Industry," in D.

M ookherjee (ed.), Indian Industry: Policies and Performance, Oxford

University Press.

Perry, M . K. and Porter, R. H. [1985], "Oligopoly and Incentives for Horizontal M erger," American Economic Review 75; pp. 219-227.

Reserve Bank of India [1968-85], Foreign Collaboration in Indian industry

(First through Fourth Survey), Bombay.

Reynolds, R. and Snapp, B. [1986], "The Competitive Effects of Partial Equity Interests and Joint Ventures," International Journal of Industrial Organization 4; pp. 141-153.

Rockett, K. [1990], "The Quality of Licensed Technology," International Journal of Industrial Organization 8; pp. 559-574.

Roy, M. [1997], "M ergers and Takeovers: The Indian Scene During Nineties," mimeo, Centre for Studies in Social Sciences, Calcutta.

Salant, S. W., Switzer, S. and Reynolds, R. [1983], "Losses from Horizontal Merger: The Effects of an Exogenous Change in Industry Structure on Cournot-Nash Equilibrium," Quarterly Journal of Economics 98; pp. 185-199.

Tang, M . and Yu, J. [1990], “F oreign M arket Entr y, Product Related Strategies" M anagement Science 36; pp. 476-489.

Telesio, P. [1979], Technology Licensing and Multinational Enterprises, New York: Praeger.

Zhao, L. [1997], "International J oint Ventures and Endogenous Protection: A Political-E conomy A pproach," Journal of E conomic Integration 12; pp. 548-560. 


\section{Appendix A}
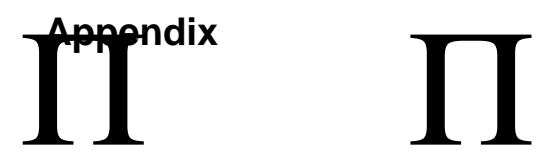

Proof of Proposition 1:

From equations (2.5) and (2.6), $\forall c \in\left(c_{1}, c^{*}\right),\left(\Pi^{\top}-\Pi^{N}\right)$ is quadratic and continuous in c with

$$
\left.\left({ }^{T}-{ }^{N}\right)\right|_{c=c_{l}}=0,\left.\left({ }^{T}-{ }^{N}\right)\right|_{c=c^{*}}>0 \text { and }\left.\frac{\left({ }^{T}-{ }^{N}\right)}{c}\right|_{c=c_{l}}>0
$$

Therefore $\forall c \in\left(c_{1}, c^{*}\right),\left(\Pi^{\top}-\Pi^{N}\right)>0 . B$ ut $\forall c \in\left[c^{*}, \bar{c}\right), \Pi^{\top}$ is constant. Hence

$$
\left.\left({ }^{T}-{ }^{N}\right)\right|_{c=c^{*}}>0 \text { and }\left.\left({ }^{T}-{ }^{N}\right)\right|_{c=\bar{c}}<0
$$

Also $\Pi{ }^{N}$ is quadratic and continuous in $c$. Therefore $\exists c_{t}, c^{*}<c_{t}<\bar{c}$ such that $\Pi^{\top}>\Pi^{N} \forall c \in\left(c_{1}, c_{t}\right)$

\section{Appendix B}

Proof of Proposition 2:

From equations (2.5) and (2.8), $\left(\Pi^{\mathrm{M}}-\Pi^{\mathrm{N}}\right)$ is quadratic and continuous in $\mathrm{c}$. Hence

$$
\left.\left({ }^{N}-{ }^{M}\right)\right|_{c=c_{l}}>0,\left.\left({ }^{N}-{ }^{M}\right)\right|_{c=\bar{c}}=0 \text { and }\left.\frac{\left({ }^{N}-{ }^{M}\right)}{c}\right|_{c=\bar{c}}>0
$$

Therefore, $\exists c_{m}$ such that $\forall c \in\left(c_{m}, \bar{c}\right)$, merger is profitable.

\section{Appendix C}

Proof of Proposition 3:

$$
\text { When } m=2 \text {, }
$$

From equations (2.5) and (2.9) $\forall c \in\left(c_{1}, c^{*}\right)$ we get $\left(\Pi^{J}-\Pi^{N}\right)$ is quadratic and continuous in $\mathrm{c}$. Then

$$
\left.\left({ }^{J}-{ }^{N}\right)\right|_{c=c_{l}}<0 \text { and }\left.\left({ }^{J}-{ }^{N}\right)\right|_{c=c^{*}}>0
$$


Therefore, $\exists c_{j}, c_{1}<c_{j}<c^{*}$ such that $\forall c \in\left(c_{j}, c^{*}\right),\left(\Pi^{j}-\Pi^{N}\right)>0$. Also $\Pi^{J}=\Pi^{\top}$ $\forall c \in\left[c^{*}, \bar{c}\right)$ and $\forall c \in\left[c^{*}, c_{t}\right), \Pi^{\top}>\Pi^{N}\left(\right.$ From appendix A). Similarly, $\forall c \in\left[c^{*}\right.$, $\left.c_{t}\right), \Pi^{j}>\Pi^{N}$. Therefore, $\forall c \in\left(c_{j}, c_{t}\right), \Pi^{J}>\Pi^{N}$.

When $m \geq 3$,

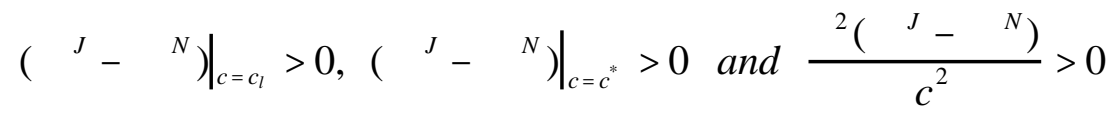

Again $\left(\Pi^{J}-\Pi^{N}\right)$ is quadratic and continuous $\forall c \in\left[c_{1}, c^{*}\right)$. Therefore, ( $\Pi^{J}-$ $\left.\Pi^{N}\right)$ is convex over the range $\left(c_{1}, c^{*}\right)$ and

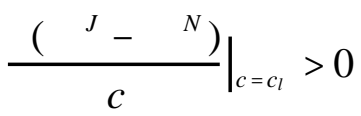

Hence it has no root in that range. This implies that $\Pi^{J}$ and $\Pi^{N}$ has no intersection between $\left(c_{1}, c^{*}\right)$. Again $\Pi^{J}=\Pi^{\top} \forall c \in\left[c^{*}, \bar{c}\right)$ and $\Pi^{\top}>\Pi^{N} \forall c \in$ $\left[c^{*}, c_{1}\right)$. Therefore, $\Pi^{j}>\Pi^{N} \forall c \in\left[c^{*}, c_{t}\right)$. And, also $\Pi^{\prime}>\Pi^{N} \forall c \in\left[c_{1}, c_{t}\right)$

\section{Appendix D}

Proof of Proposition 4:

When $\mathrm{m}=2$,

$$
\begin{aligned}
& \left.\left({ }^{T}-{ }^{N}\right)\right|_{c=c_{l}}=0,\left.\left({ }^{J}-{ }^{M}\right)\right|_{c=c_{l}}>0,\left.\left({ }^{T}-{ }^{J}\right)\right|_{c=c_{l}}>0, \\
& \left.\left({ }^{T}-{ }^{J}\right)\right|_{c=c^{*}}=0 \text { and }\left.\frac{\left({ }^{T}-{ }^{J}\right)}{c}\right|_{c=c^{*}}<0
\end{aligned}
$$

$\left(\Pi^{\top}-\Pi^{J}\right)$ is quadratic and continuous in $c$. Hence $\forall c \in\left(c_{1}, c^{*}\right),\left(\Pi^{\top}-\Pi^{s}\right)>0$ (where $s=N, M, J$ ). Existence of $c^{1}<c_{t}$ is obvious from the earlier appendices.

When $m \geq 3$,

$$
\left.\left({ }^{T}-{ }^{J}\right)\right|_{c=c_{l}}<0,\left.\left({ }^{T}-{ }^{J}\right)\right|_{c=c^{*}}=0 \text { and }\left.\frac{\left({ }^{T}-{ }^{J}\right)}{c}\right|_{c=c^{*}}<0
$$

$\Pi^{J}-\Pi^{\top}$ is quadratic and continuous in c. Therefore, $\exists c^{2}, c_{1}<c^{2}<c_{m}$, such that $\forall c \in\left(c_{1}, c^{2}\right), \Pi^{j}>\Pi^{\top}$ and $\forall c \in\left(c^{2}, c^{*}\right), \Pi^{\top}>\Pi^{J}$. At $c_{m}, \Pi^{\top}>\Pi^{J}$. Hence, $c_{m}>c^{2}$. Existence of $\hat{c}$ is obvious from the earlier appendices. 


\section{Appendix E}

Proof of Proposition 5:

We have

$$
\begin{aligned}
& \left.\left(W^{T}-W^{N}\right)\right|_{c=c_{l}}=0 \text { and }\left.\left(W^{T}-W^{N}\right)\right|_{c=c^{*}}>0 \\
& \left.\frac{\left(W^{T}-W^{N}\right)}{c}\right|_{c=c_{l}}<0 \quad \text { for } m=2 \\
& \left.\frac{\left(W^{T}-W^{N}\right)}{c}\right|_{c=c_{l}} \geq 0 \quad \text { for } m \geq 3
\end{aligned}
$$

$W^{\top}-W^{N}$ is quadratic and continuous in $c . \forall c \in\left(c_{1}, c^{*}\right)$,

For $m=2$,

$\exists c_{w}^{1}, c_{1}<c_{w}^{1}<c^{*}$, such that $\forall c \in\left(c_{w}^{1}, c^{*}\right), W^{\top}>W^{N}$,

and for $m \geq 3$,

$\forall c \in\left(c_{1}, c_{w}^{*}\right), W^{\top}>W^{N}$.

Again for $m \geq 2$,

$$
\left.\left(W^{T}-W^{N}\right)\right|_{c=c^{*}}>0,\left.\left(W^{T}-W^{N}\right)\right|_{c=\bar{c}}>0 \text {, and } \frac{{ }^{2}\left(W^{T}-W^{N}\right)}{c^{2}}<0 .
$$

For $m>2, \forall c \in\left[c^{*}, c_{t}\right), W^{\top}>W^{N}$.

\section{Appendix F}

Proof of Proposition 6:

If $\mathrm{m}=2$,

$\left.\left(W^{M}-W^{N}\right)\right|_{c=c_{l}}<0,\left.\left(W^{M}-W^{N}\right)\right|_{c=\bar{c}}=0$ and $\left.\frac{\left(W^{M}-W^{N}\right)}{c}\right|_{c=\bar{c}}>0$

As $\left(W^{M}-W^{N}\right)$ is quadratic and continuous in $c, \forall c \in\left(C_{m}, \bar{c}\right), W^{N}-W^{M}$.

If $m \geq 3$,

$$
\begin{aligned}
& \left.\left(W^{M}-W^{N}\right)\right|_{c=c_{l}}>0,\left.\left(W^{M}-W^{N}\right)\right|_{c=c^{*}}<0, \\
& \left.\left(W^{M}-W^{N}\right)\right|_{c=\tau}=0 \text { and }\left.\frac{\left(W^{M}-W^{N}\right)}{c}\right|_{c=c}>0 .
\end{aligned}
$$


As $\left(W^{M}-W^{N}\right)$ is quadratic and continuous in $c, \exists c_{W}, c_{1}<c_{W}<c^{*}$, such that $\forall c \in\left[c_{w}, \bar{c}\right), W^{N}>W^{M}$. Now for $m \geq 4$, at $c_{m}, W^{M}>W^{N}$. Therefore, $c_{w}>c_{m}$. For $m=3, \forall c \in\left(c_{m}, \bar{c}\right), W^{N}>W^{M}$. Thus for $m=2, \forall c \in\left(c_{m}, \bar{c}\right), W^{N}>W^{M}$ but for $m \geq 4, \forall c \in\left(c_{m}, c_{w}\right), W^{M}>W^{N}$.

\section{Appendix G}

Proof of Proposition 7.

$$
\begin{aligned}
& \left.\left(W^{J}-W^{N}\right)\right|_{c=c_{l}}>0,\left.\left(W^{J}-W^{N}\right)\right|_{c=c^{*}}>0, \\
& \left.\frac{\left(W^{J}-W^{N}\right)}{c}\right|_{c=c_{l}}<0, \frac{{ }^{2}\left(W^{J}-W^{N}\right)}{c^{2}}>0 \text { and }\left.\frac{\left(W^{J}-W^{N}\right)}{c}\right|_{c=c^{*}}>0
\end{aligned}
$$

As $\left(W^{J}-W^{N}\right)$ is quadratic and continuous in $c_{,}\left(W^{J}-W^{N}\right)$ attains its minimum. But $\min \left(W^{J}-W^{N}\right)>0$. Therefore, $\left(W^{J}-W^{N}\right)$ has no root in the range $\left(c_{1}, c^{*}\right)$. Also $\forall c \in\left(c^{*}, c_{t}\right), W^{J}>W^{N}$. Hence $\forall c \in\left(c_{1}, c_{t}\right), W^{J}>W^{N}$.

\section{Appendix H}

Proof of Proposition 8

$$
\left.\left(W^{J}-W^{T}\right)\right|_{c=c_{l}}>0,\left.\left(W^{J}-W^{T}\right)\right|_{c=c^{*}}=0 \text { and }\left.\frac{\left(W^{J}-W^{N}\right)}{c}\right|_{c=c^{*}}<0 .
$$

Again $W^{J}-W^{\top}$ is quadratic and continuous in $c$. Therefore $\forall c \in\left(c_{1}, c^{*}\right)$, $W^{J}>W^{\top}$. And $\forall c \in\left[c^{*}, c_{t}\right), W^{J}=W^{\top}$. 